\title{
El tránsito neolítico-calcolítico en el sureste de Córdoba. Su evolución y desarrollo: La Mesa (Fuente-Tójar, Córdoba)
}

\author{
María R. Delgado Fernández *
}

\section{INTRODUCCION:}

Es nuestra intención elaborar una breve aproximación al tránsito entre las primeras sociedades productoras y las culturas de la metalurgia en el sector sureste de la provincia de Córdoba a partir del análisis particular del Subbético cordobés ${ }^{1}$.

Hemos de señalar que esta zona ha sido objeto de un amplio interés científico en los últimos años, especialmente reflejado en el estudio sistemático de las primeras culturas productoras; sin embargo, el conocimiento de etapas cronológicas posteriores es mucho más difuso y fragmentario, salvo excepciones puntuales que carecen en todo caso de valoraciones de conjunto. Ante esta situación, decidimos continuar la definición de la Prehistoria Reciente en la Subbética Cordobesa, abordando como yacimiento-marco el asentamiento de La Mesa (Fuente-Tójar) para efectuar una aproximación al tránsito Neolítico-Calcolítico en este sector, dado su cuantioso y significativo material, su privilegiada situación y la poco deseada frecuentación por los aficionados locales.

\section{EL MEDIO FISICO}

Las Cordilleras Subbéticas constituyen una de las tres grandes unidades geomorfológicas que se pueden distinguir a nivel provincial: Sierra Morena,

* Becaria F.P.I. Universidad de Córdoba. Area de Prehistoria, Facultad de Filosofía y Letras. Pl. Cardenal Salazar, 3. 14071. Córdoba. Telf.: (957) 21-88-08.

1 El presente trabajo es un resumen de nuestra Memoria de Licenciatura, defendida en 1995 en la Universidad de Córdoba. 
la Campiña y las Subbéticas. A pesar de su continuidad, existe una gran hetereogeneidad estructural, litológica y topográfica (Díaz del Olmo y Alvarez, 1989). Nuestra zona de estudio se asienta sobre el denominado Subbético Externo y, por tanto, se caracteriza por la enorme abundancia de afloramientos calizos que conforman un relieve muy característico, de cotas medias en torno a los $1000 \mathrm{~m}$.

En líneas generales, podemos disociar tres grandes dominios (Ortega Alba, 1974): el espolón montañoso SE-NO, con varias alineaciones separadas por pasillos más o menos estrechos, como el Macizo de Cabra, el pasillo de Carcabuey, las alineaciones centro-meridionales, el pasillo del Salado y la alineación Albayate-Loma de las Ventanas; la depresión triásica Priego-Alcaudete y, finalmente, el piedemonte del Oeste, única zona con predominio de llanuras o terrenos de menor altura.

Debido a esta variedad de afloramientos litológicos, encontramos una gran hetereogeneidad en la distribución de los suelos. En líneas generales, encontramos que los suelos margoyesosos y regosuelos se encuentran bien representados en el NE. de la Comarca, en los alrededores de Fuente-Tójar y en la línea Rute-Horconera, en cambio, el grupo de las rendsinas aparecen en Fuente-Tójar, Priego, Almedinilla y gran parte del Sur. Por otro lado, las extensiones de suelos rojos no son frecuentes pero se localizan dos áreas importantes, entre Benamejí-Encinas Reales y al Norte de Fuente-Tójar. Por último, en los pequeños valles de los ríos se encuentran zonas reducidas de vega.

De otro lado, el primigenio bosque mediterráneo era muy diferente del actual debido a la acción destructora o degenerativa del hombre que ha irrumpido en el ecosistema cambiando las tendencias naturales. En la Comarca podemos encontrar desde el bosque puro, pasando por los diferentes estadios de degeneración, hasta algunos biotopos más o menos endémicos. Desde el punto de vista de la variedad florística, esta zona hace gala de una riqueza desconocida en el resto del territorio provincial. Las comunidades vegetales arbóreas pertenecen al dominio oleo-quercinio, reducidas a pocos testimonios en las cumbres serranas; en cambio, la vegetación arbustiva, representada por retamas, aulagas, cornicabras, Ientiscos,... es bastante más abundante. Pero, hoy en día, la desforestación y la roturación llevadas a cabo desde la antigüedad han transformado el paisaje en amplios olivares, siendo también importantes algunas extensiones de cereal, viñedo, hortalizas y frutales (C.E.B.A.C., 1971).

\section{EL ASENTAMIENTO DE LA MESA}

La Mesa se localiza en la Hoja 968 (Alcaudete) del M.T.N., escala 1:50.000, en las coordenadas $37^{\circ} 30^{\prime} 40^{\prime \prime} \mathrm{N}$ y $0^{\circ} 28^{\prime} 0^{\prime \prime} \mathrm{W}$. El asentamiento 
se encuentra en una amplia meseta o cerro amesetado de unos 680-700 $\mathrm{m}$. de altitud, aproximadamente, situada al Noroeste del casco urbano de Fuente-Tójar. En la actualidad, la meseta se encuentra parcialmente repoblada por pinos en el sector Norte y, por lo demás, está íntegramente destinada al cultivo del olivar.

Así pues, las condiciones de habitabilidad son óptimas, a las que se unen las estratégicas. Se presenta prácticamente inexpugnable por tres de sus frentes, abriéndose pequeñas covachas y grietas en los escarpados tajos, controla un paso natural y la cercana confluencia del curso del San Juan con el Salado, que discurre por su base, permitiendo el desarrollo de una fértil vega. Hacia el Norte se domina una enorme extensión abierta y relativamente llana; hacia el Sur, sierras escarpadas y estrechos pasos.

Por otra parte, la importancia del asentamiento de La Mesa ya fue valorada por J. Martínez Santa-Olalla (1935), que tuvo ocasión de conocer algunos materiales durante sus intervenciones arqueológicas en el Cerro de las Cabezas (Fuente-Tójar) y la cueva de los Mármoles (Priego de Córdoba). Constató la existencia de una gran abundancia de cerámica lisa y una importante industria lítica. Posteriormente, contamos también con algunas referencias sobre el mismo en el trabajo de Bernier et al. sobre los yacimientos inéditos de las provincias de Córdoba y Jaén (Bernier, Sánchez, Jiménez, Sánchez, 1981) y Murillo (1990).

Así pues, para abordar la elaboración de este trabajo hemos acometido la labor de descripción y análisis de todo aquel material del que hemos tenido constancia, incluyendo varias colecciones particulares, por tanto, el carácter de la documentación ha sido y es un serio obstáculo para este reconocimiento. Esperamos que futuros trabajos de campo nos brinden la posibilidad de comprobar, corroborar o, en su caso, modificar estos planteamientos a la luz de nuevas evidencias.

De esta forma, hemos seguido un método estadístico por considerar que es el más objetivo para describir y analizar este tipo de materiales carentes de contexto y teniendo en cuenta, sobre todo, su volumen ${ }^{2}$. Por el contrario, en los casos de reducida cuantía, hemos optado por los valores absolutos para evitar la sobre-representación que supondría su tratamiento estadístico.

\footnotetext{
2 En este sentido, hemos seguido la metodología planteada por la Dra. AsQuERINo (1978) y también, en líneas generales, por la Dra. GAVILÁN (1989) a las que nos remitimos.
} 
De este modo, el material en estudio, 3790 piezas, lo hemos subdividido en varios subapartados en función de la materia prima utilizada, de sus características y su posible funcionalidad: industria lítica tallada, piedra pulimentada y trabajada, material exógeno, cerámica, adorno, metal, adobe y varios. En la siguiente tabla y en gráfico contiguo, presentamos el conjunto de la muestra analizada con el reparto proporcional de los diferentes grupos, que, en aras de la brevedad, sólo presentaremos someramente.

TABLA I

CONJUNTO MATERIAL DE LA MESA

\begin{tabular}{lrr}
\hline IND.LIT.TALLADA & 2452 & $64,70 \%$ \\
P.TRABAJADA & 103 & $2,72 \%$ \\
M.EXOGENO & 189 & $4,99 \%$ \\
CERAMICA & 1015 & $26,78 \%$ \\
ADORNO & 23 & $0,61 \%$ \\
METAL & 2 & $0,05 \%$ \\
ADOBE & 1 & $0,03 \%$ \\
VARIOS & 5 & $0,13 \%$ \\
TOTAL & 3790 & $100 \%$ \\
\hline
\end{tabular}

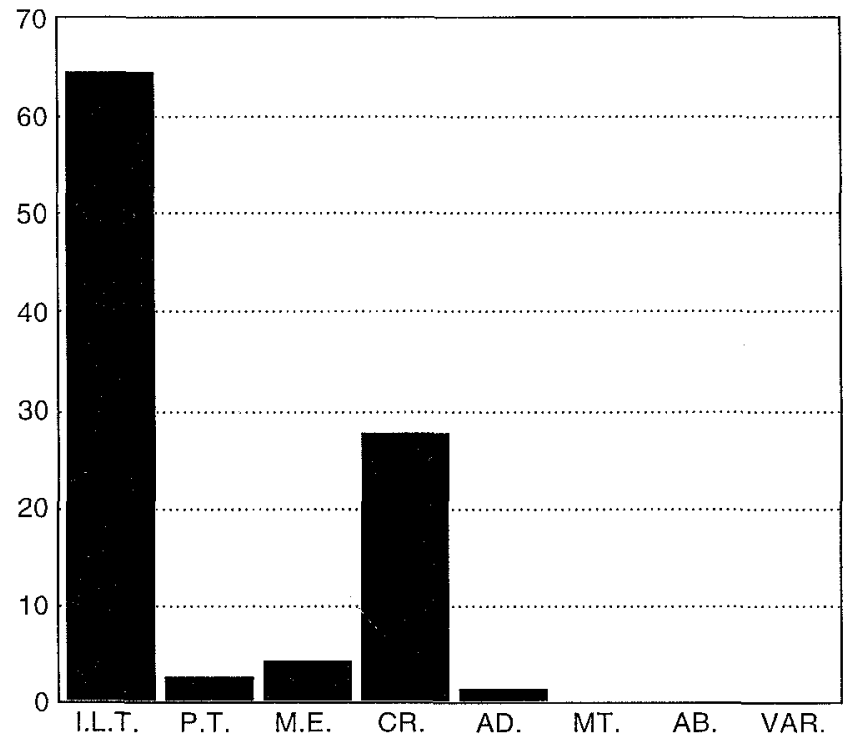

Gráfico 1. I.L.T. Lítica Tallada; P.T.: Piedra Trabajada; M.E.: Material Exógeno; CR.: Cerámica; AD.: Adorno; MT.: Metal; AB.: Adobe; Var.: Varios. 
En el capítulo de la industria lítica tallada, que alcanza el $64,70 \%$ del total del conjunto material, se observa un claro predominio del material no retocado sobre el retocado, lógico si tenemos en cuenta que los fragmentos informes alcanzan el $40 \%$ de total, constatándose el empleo del sílex como la materia prima generalizada $(99,88 \%)$.

Se trata de una industria retocada marcadamente laminar, sin alcanzar altos porcentajes de útiles tipológicos. Hemos de destacar el utillaje dedicado a actividades agrícolas de recolección, como son los dientes de hoz, característicos de momentos calcolíticos (Fig. 1), acompañados de tipos adaptados a la defensa y/o explotación cinegética del entorno, como son las puntas de flecha (Fig. 2), cuya presencia parece constatarse, según las estratigrafías, a partir del Calcolítico Antiguo y continúan a lo largo de las secuencias, sin faltar los elementos de utillaje de transformación, como los raspadores (Fig. 2), perforadores y taladros (Fig. 3), escotaduras (Fig. 4), truncaturas (Fig. 5), algunos de ellos especialmente frecuentes en el Neolítico de esta zona y, por último, una buena representación de hojas y lascas retocadas de funcionalidad diversa (Fig. 6 y 7 ).

En relación con algunos aspectos técnicos, hemos constatado la labor de talla en el asentamiento a partir de núcleos semi-preparados, en general muy agotados y de pequeñas dimensiones, productos de acondicionamiento - tabletas de reavivado, flancos de núcleo, aristas-, lascas, láminas y fragmentos informes no retocados y, finalmente, chunks. El bajo índice de lascas y hojas de descortezado es lo que nos hace pensar que probablemente los núcleos se transportaran ya semipreparados 0 , al menos, desbastados en el momento inicial de su talla.

De otro lado, los elementos de industria lítica pulimentada y trabajada nos habla de otras actividades económicas diversas, siendo su representación del $2,72 \%$ en el conjunto material. En primer lugar, contamos con los típicos elementos desforestadores, como las hachas y las azuelas, que alcanzan los índices de mayor frecuencia, junto a elementos activos y pasivos de molturación dedicados al procesamiento de recursos vegetales. Finalmente, el capítulo se completa con cinceles, un alisador y varios casos de piedra exógena, sin tipología definida, en los que se observa algún tipo de tratamiento o claras evidencias de uso (Fig. 8).

Con respecto al apartado cerámico (26,78\% del total), los fragmentos decorados suponen, aproximadamente, el $5 \%$ de este capítulo industrial. Las almagras son las que más se mantienen, aunque acusan una pérdida de calidad bastante notable y en ningún caso aparecen asociadas a otro sistema decorativo, junto a las decoraciones plásticas aplicadas a base de cordones y algunos motivos incisos e impresos (Fig. 9). Unido a estos materiales más relacionados con tradiciones neolíticas, otros apuntan a la 
existencia de un complejo material nuevo: amplias fuentes carenadas, definidas por carenas medias y bajas bien señaladas y bases curvas (Fig. 10), los cuencos simples, más frecuentes y característicos del Cobre y Bronce (Fig. 11), aunque también aparecen en contextos neolíticos y, finalmente, los platos de borde engrosado con grandes diámetros que presentan ligeras variantes o matices en la forma del labio.

Los sistemas de prehensión y suspensión, que suponen apenas el 3\% del conjunto de la cerámica no decorada selecta, están especialmente representados por los mamelones macizos, quedando las asas - de cinta, tubular y apéndice - con un porcentaje meramente indicativo.

Con respecto al adorno, hemos de indicar que resulta enormemente significativo en este conjunto la presencia rica y abundante de brazaletes, 23 ejemplares que supone el 0,61\% del total (Fig. 12). A pesar de su amplia cronología dentro del Neolítico, se hacen especialmente frecuentes en el Medio y se enrarecen de una forma espectacular a partir de su fase Final, por tanto, se convierten en un buen indicador cronológico y cultural para estos contextos.

A tenor de lo expuesto anteriormente, parece complicado defender a ultranza una ocupación de la Mesa en momentos avanzados del Neolítico Final con un material descontextualizado, sin embargo, es una posibilidad no descartable aunque sería del todo necesario su comprobación estratigráfica. Por el contrario, también es cierto que estos materiales de clara raigambre neolítica podrían indicarnos un fuerte peso del sustrato en etapas posteriores si tenemos en cuenta la personalidad y vigor que desarrolla el Neolítico en este ámbito.

Mayor precisión cronológica nos permiten otros componentes que tendrían plena cabida dentro de los momentos finales del Calcolítico Inicial y a lo largo del Pleno. Por el contrario, no tenemos una continuidad patente y significativa del asentamiento a partir del Cobre Final o inicios del Bronce que más bien nos hace pensar en el abandono como lugar de hábitat a partir de estos momentos.

Así pues, proponemos para este yacimiento de La Mesa una adjudicación cultural que podría haberse iniciado en los últimos momentos del Neolítico Final, desarrollándose el hábitat principalmente a lo largo del Calcolítico Inicial avanzado y Cobre Pleno, dándose posiblemente un abandono a partir del Cobre Final con pequeñas frecuentaciones como parecen demostrar la presencia de algunos materiales adscribibles a etapas posteriores.

Indiscutiblemente, este yacimiento se presenta como una de las ocupaciones calcolíticas más interesantes de este sector de la Subbética, por su magníficas condiciones de defensa natural, la posibilidad de un control rápido y directo del territorio circundante que facilita la explotación de una amplia variedad de recursos, la bonanza de sus suelos de alto valor agrícola y la existencia de cercanas vías naturales de comunicación. 
El tránsito neolítico-calcolítico en el sureste de Córdoba. Su evolución...
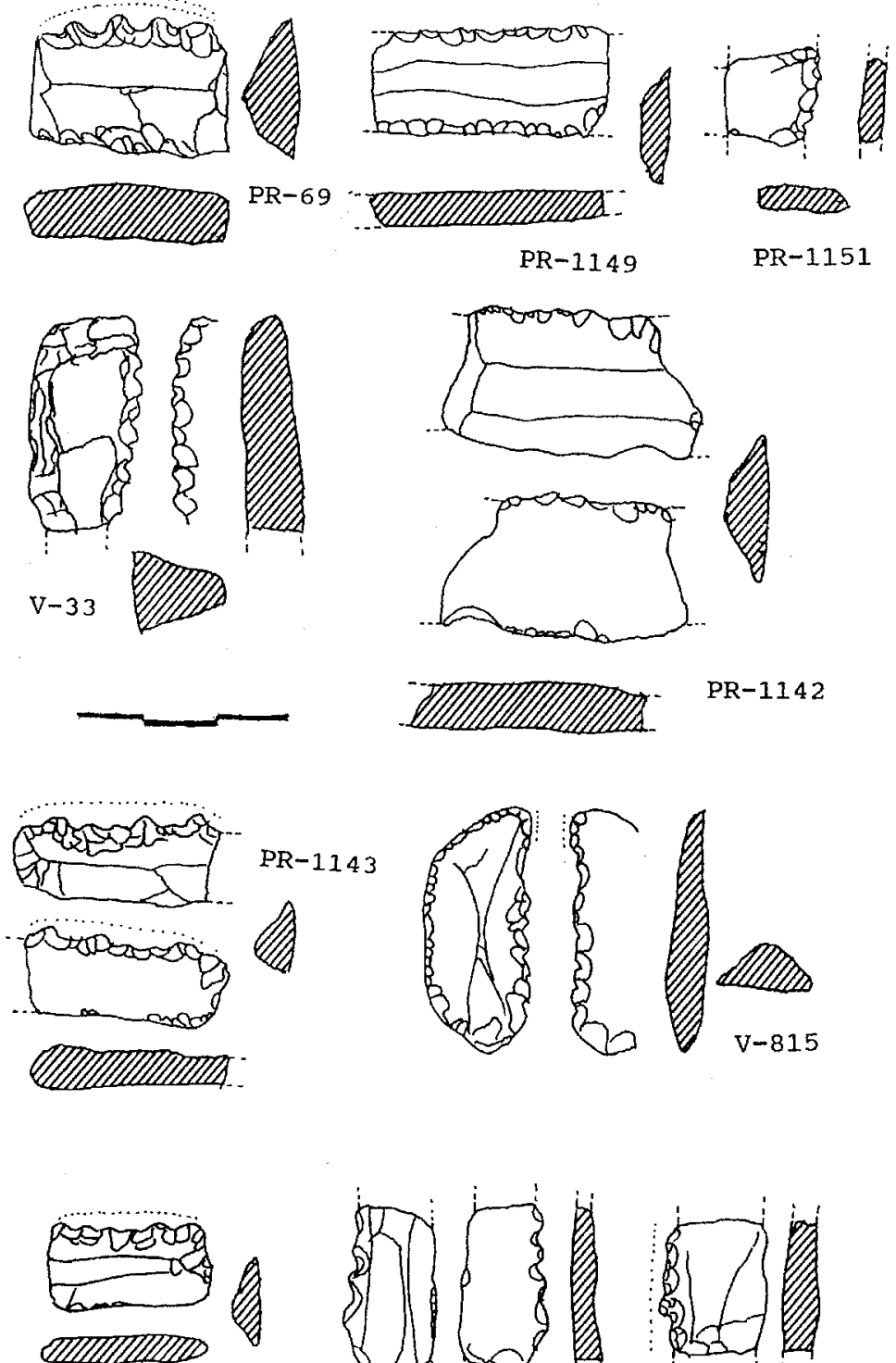

$\mathrm{PR}-99$
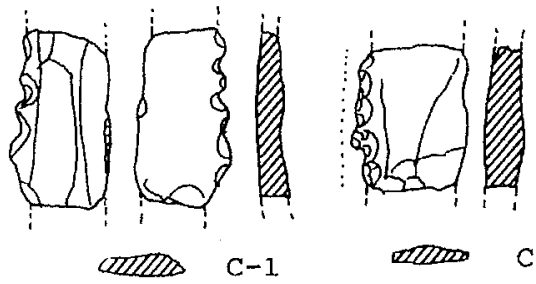

$C-2$

Figura 1. LAMESA. Dientes de hoz. 

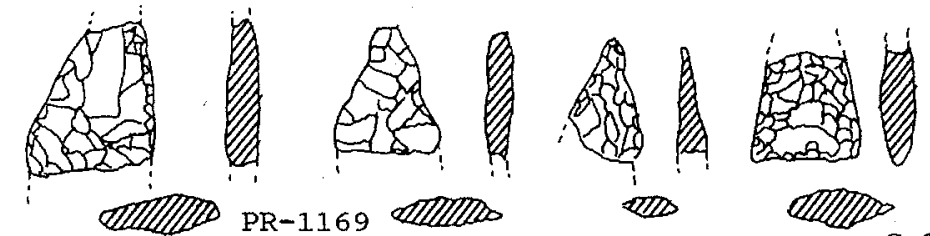

PR-1169 XIIIDO
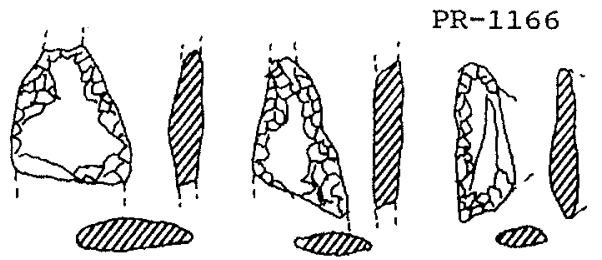

$v-23$

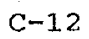

$c-13$

$\mathrm{C}-14$

$c-15$

选
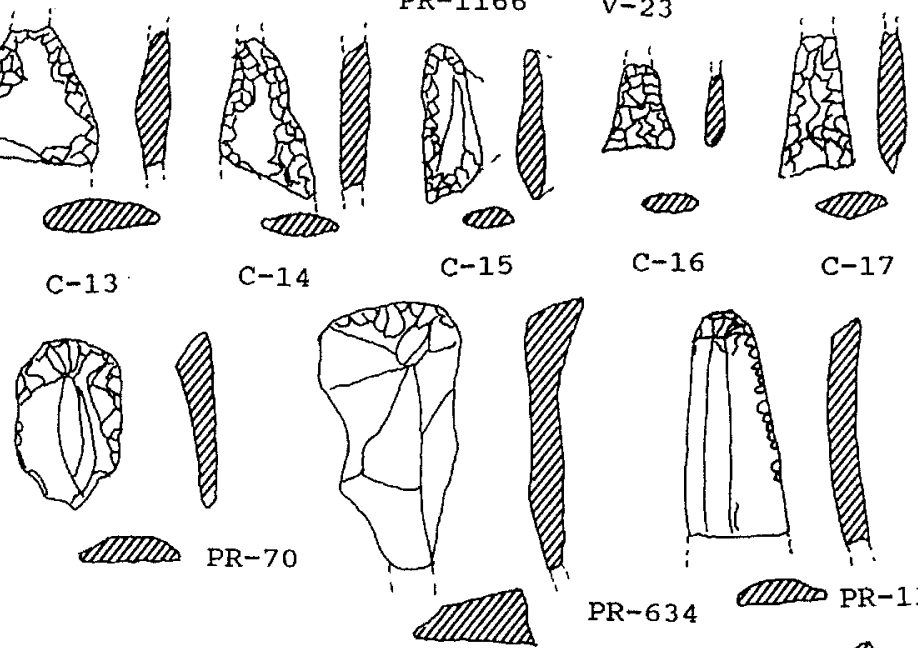

$c-16$

C-17

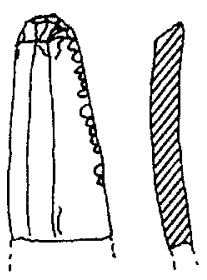

QIITOD PR-1133
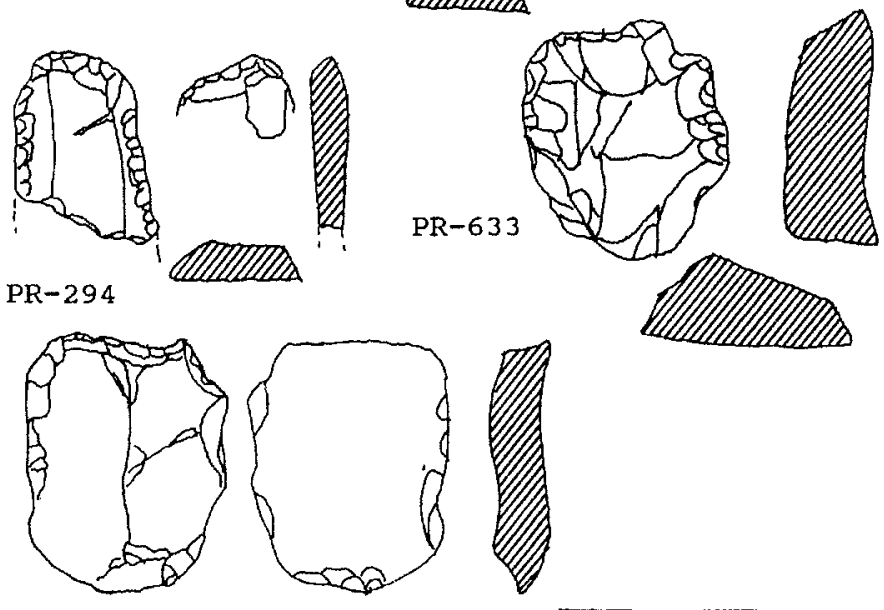

$\mathrm{V}-32$
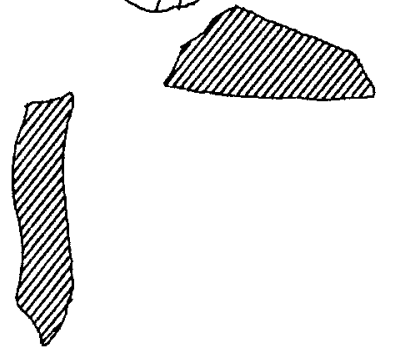

Figura 2. LA MESA. Puntas de flecha y raspadores. 

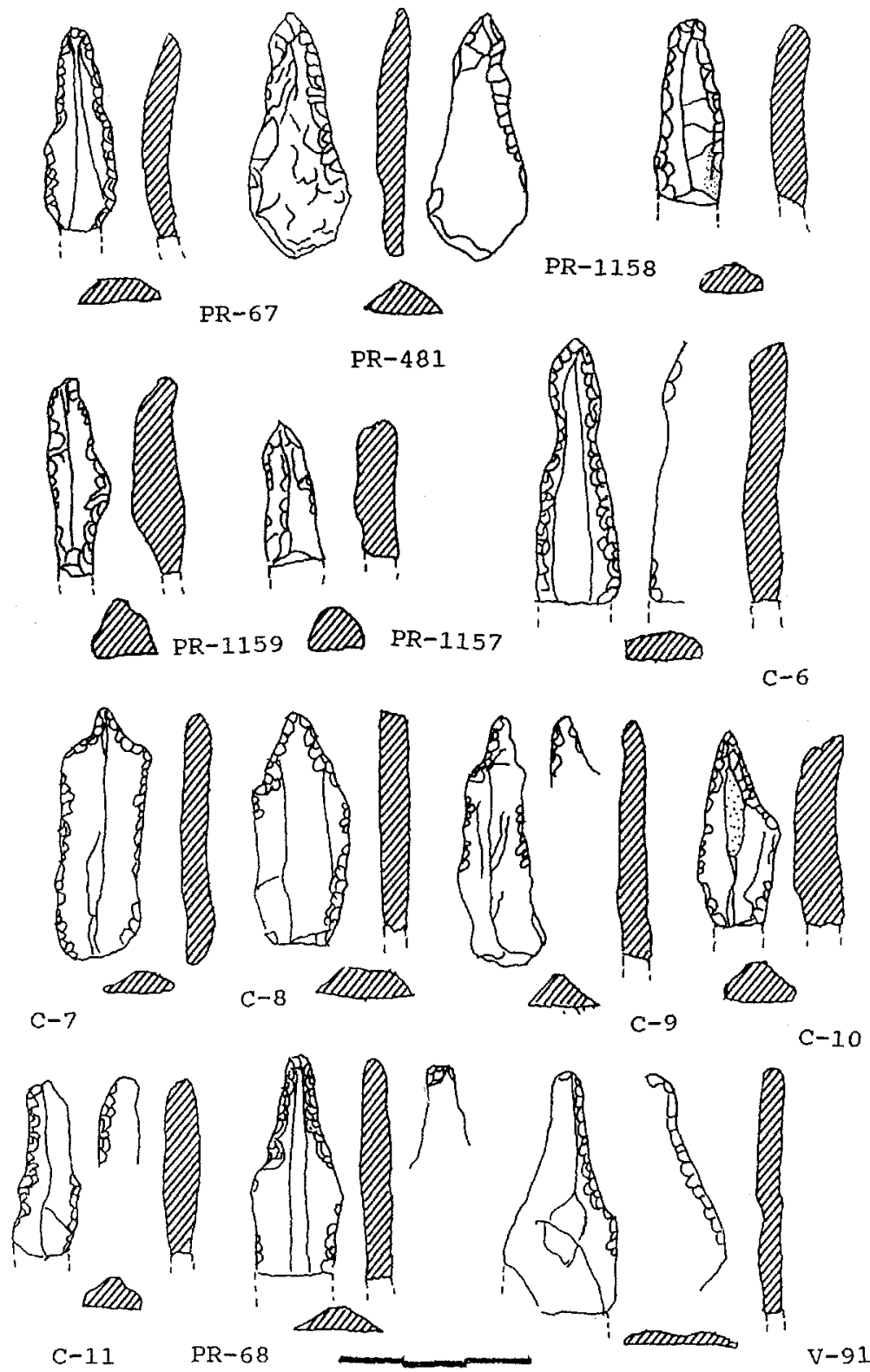

Figura 3. LAMESA. Perforadores y taladros. 


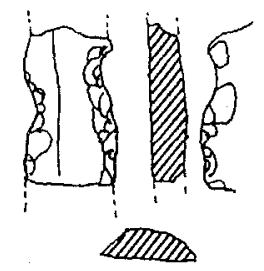

PR-6
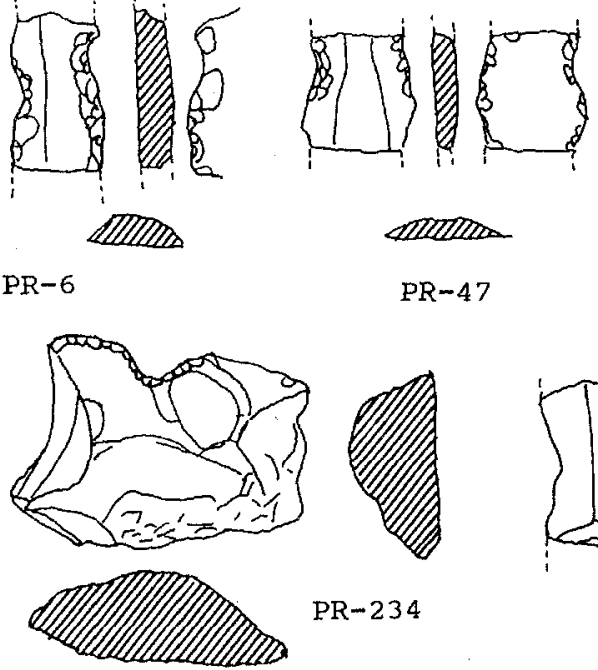

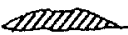

PR-47

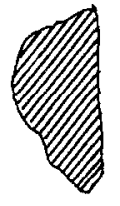

$\mathrm{PR}-234$

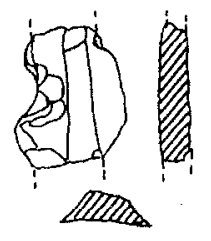

$\mathrm{PR}-385$

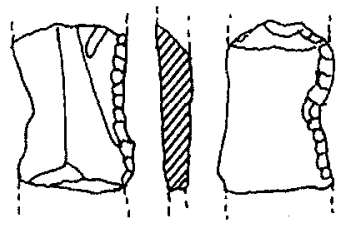

QIIIID PR-447
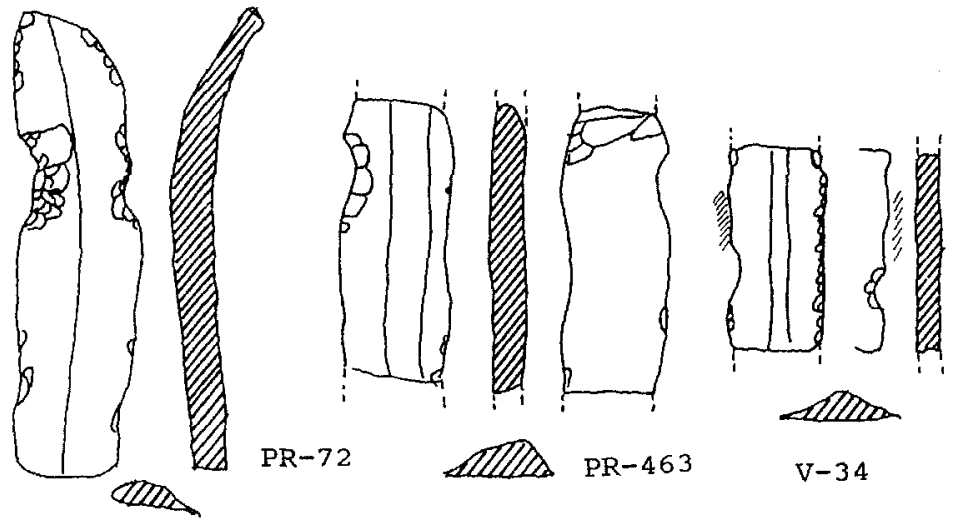

$P R-72$

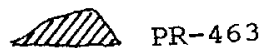

callora
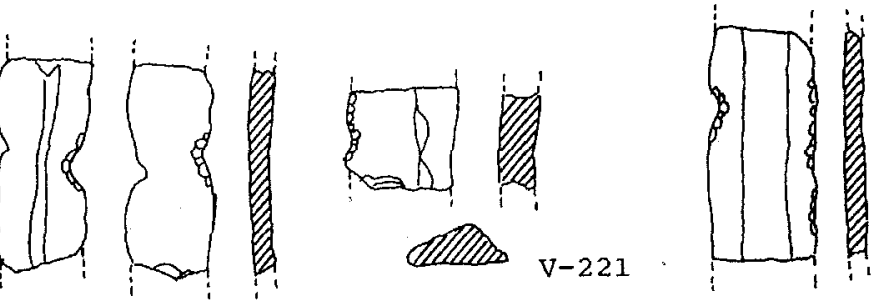

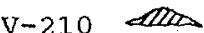

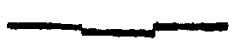

AIIIS $\mathrm{v}-74$

Figura 4. LAMESA. Escotaduras. 
El tránsito neolítico-calcolítico en el sureste de Córdoba. Su evolución...
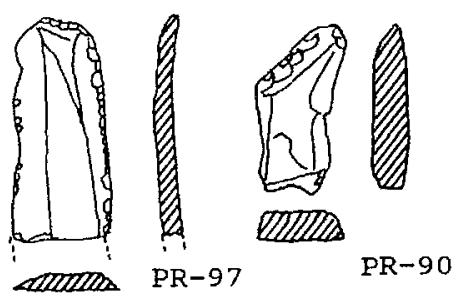

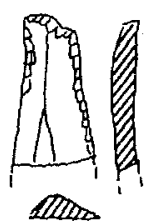

$\mathrm{PR}-104$

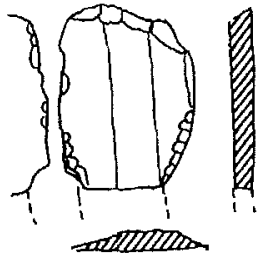

PR-164
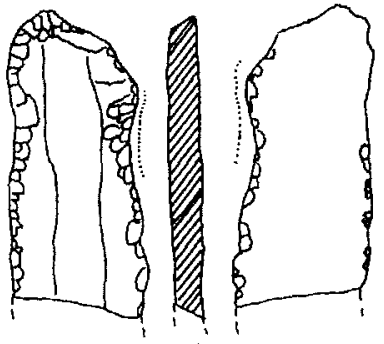

$\mathrm{PR}-173$
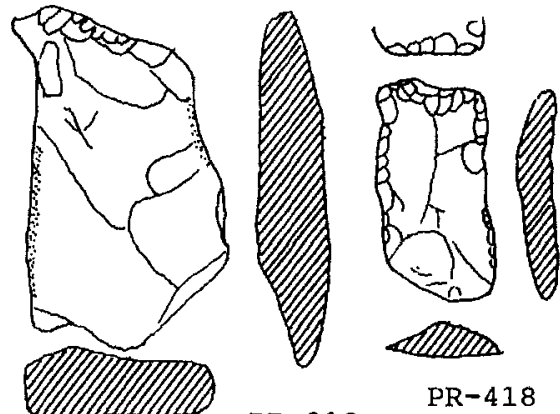

PR-319

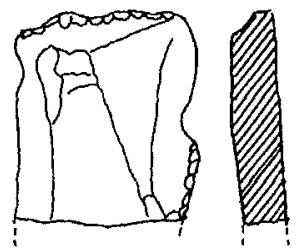

$P R-1153$

PR-615 AIIIIIIID
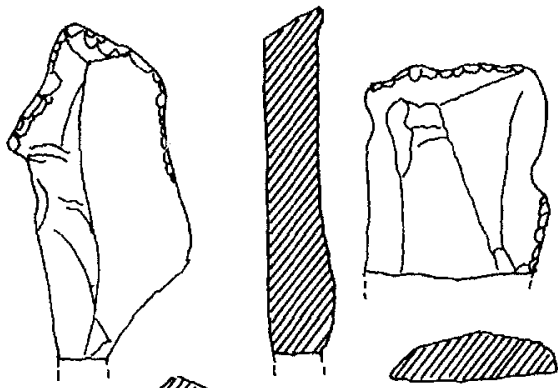

\section{s}

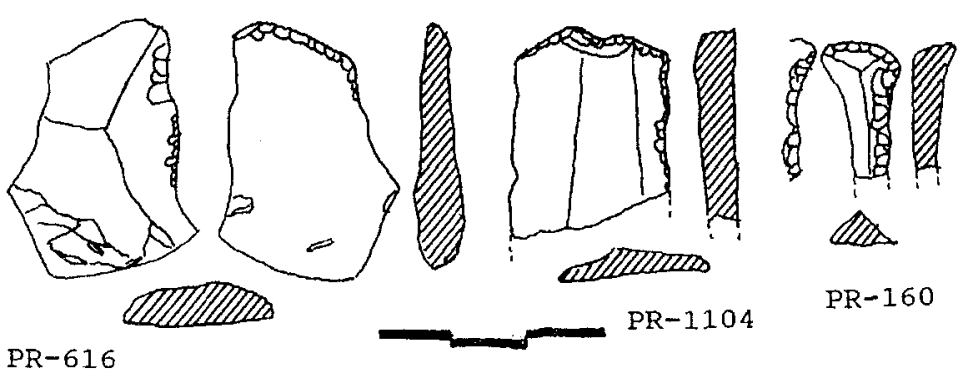

Figura 5. LAMESA. Truncaturas. 

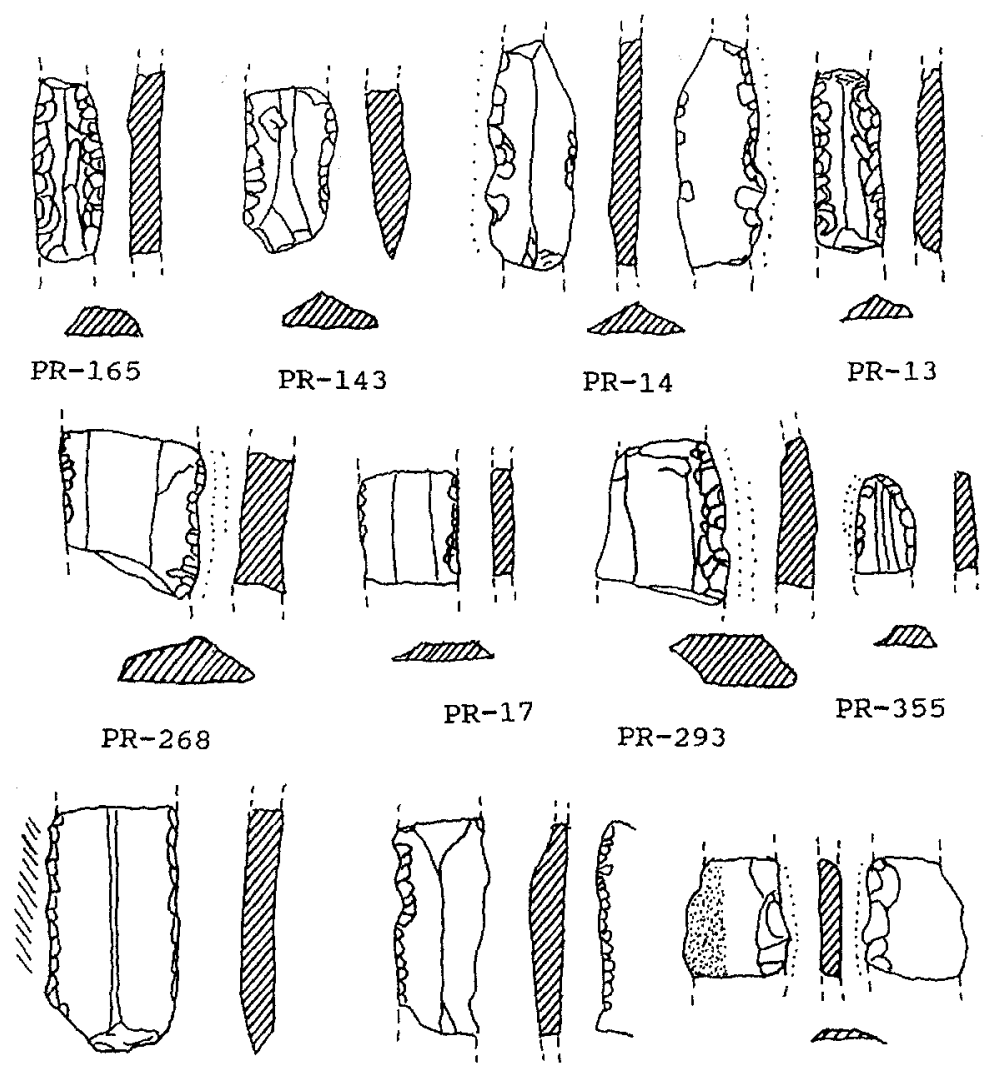

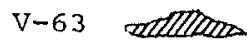
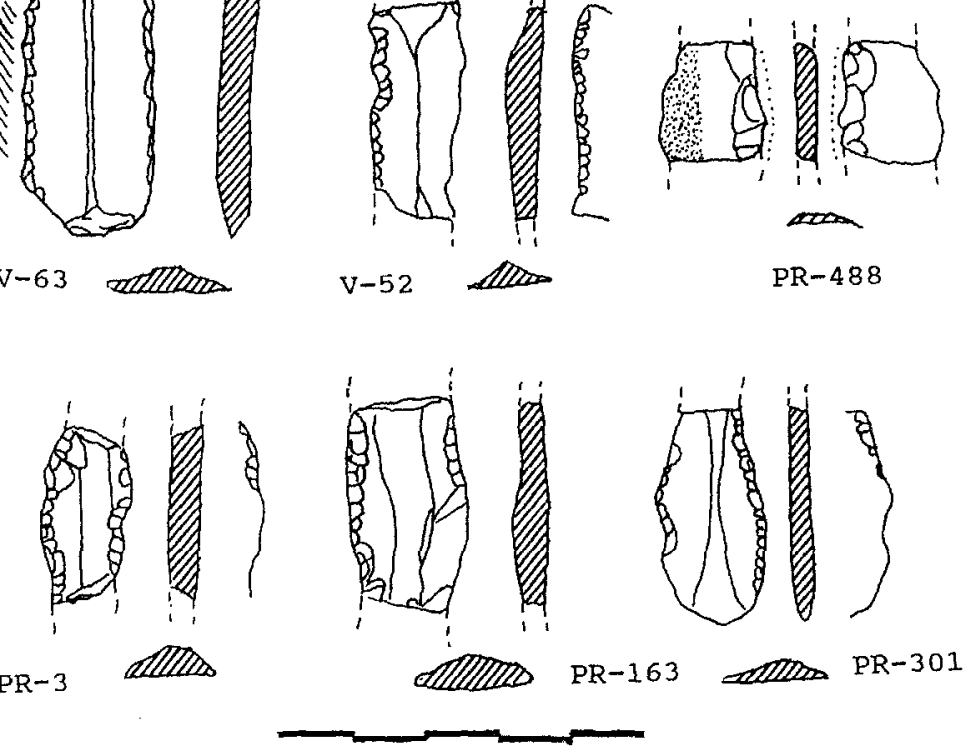

Figura 6. LA MESA. Hojas retocadas. 

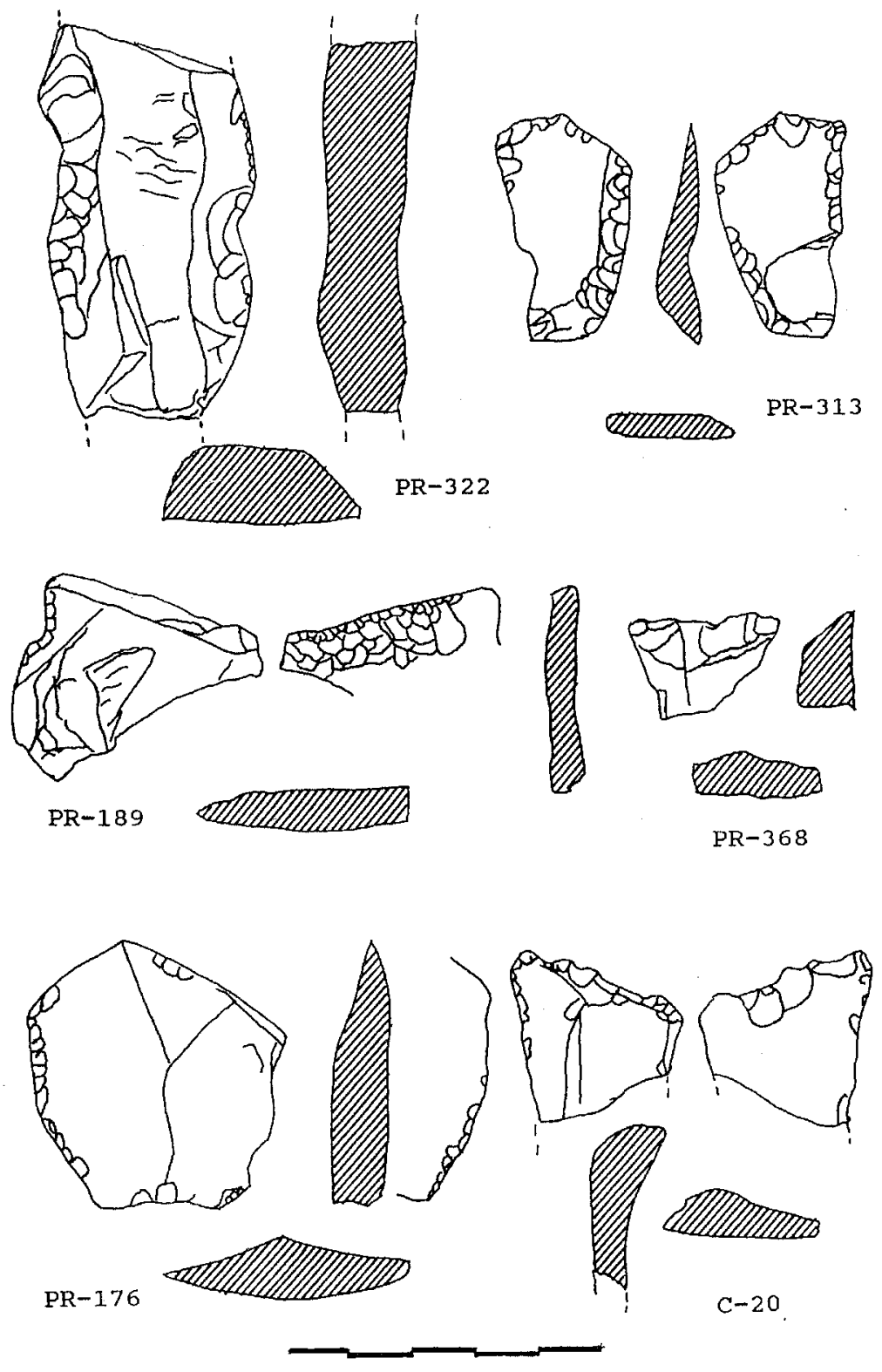

Figura 7. LAMESA. Lascas retocadas. 


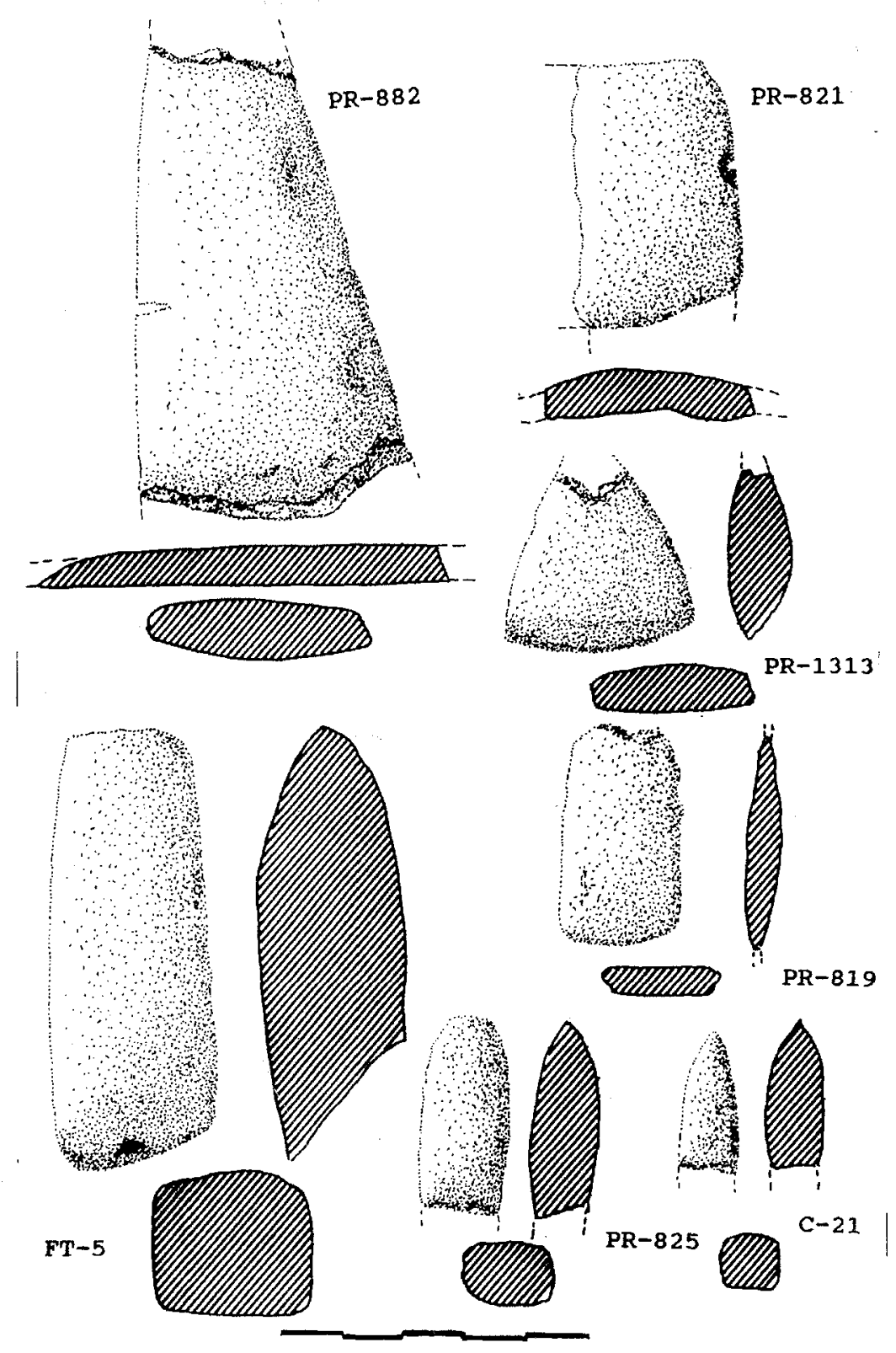

Figura 8. LA MESA. Hachas, azuelas y cinceles. 

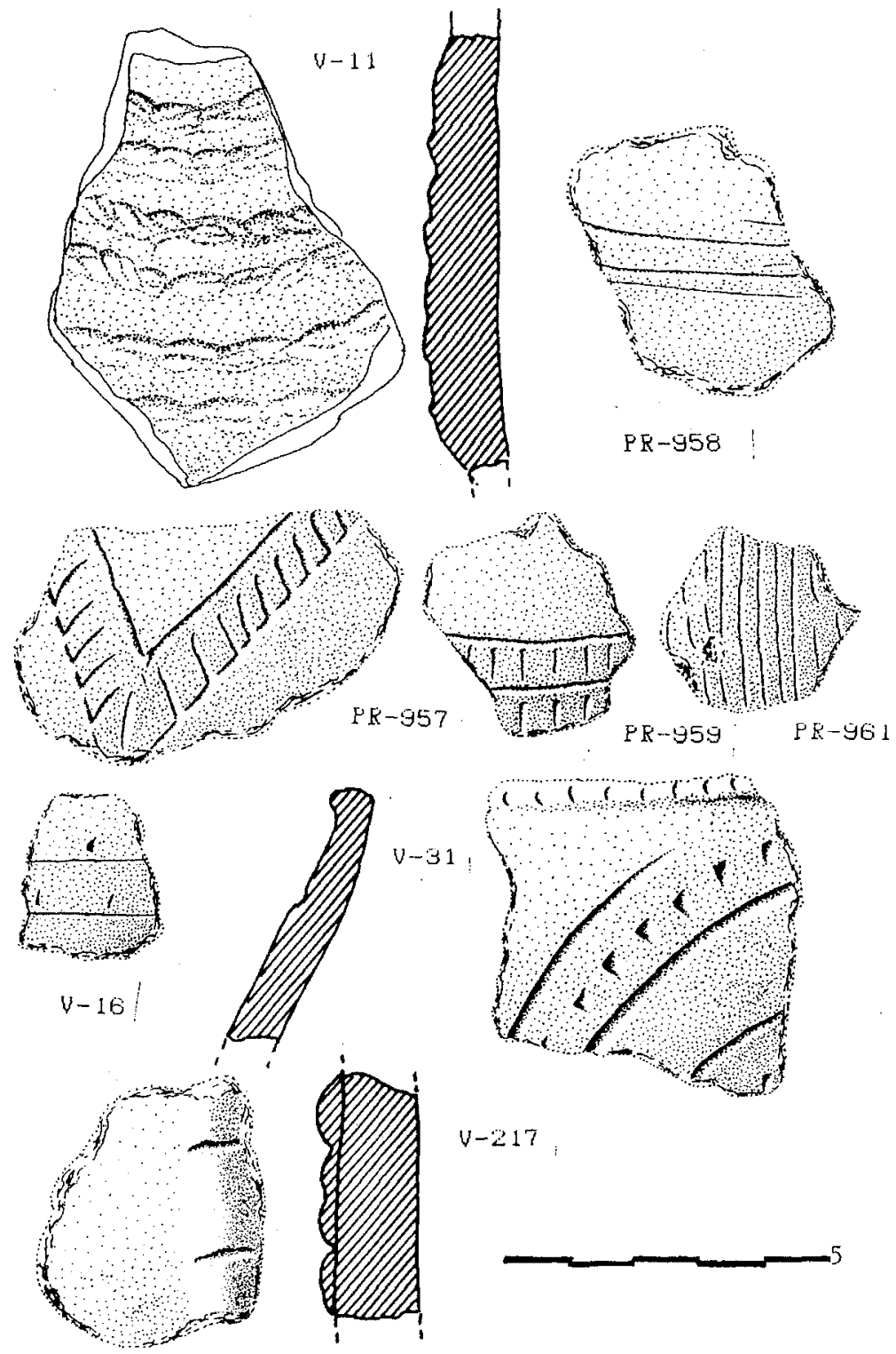

$v-217$

Figura 9. LAMESA. Cerámica decorada. 

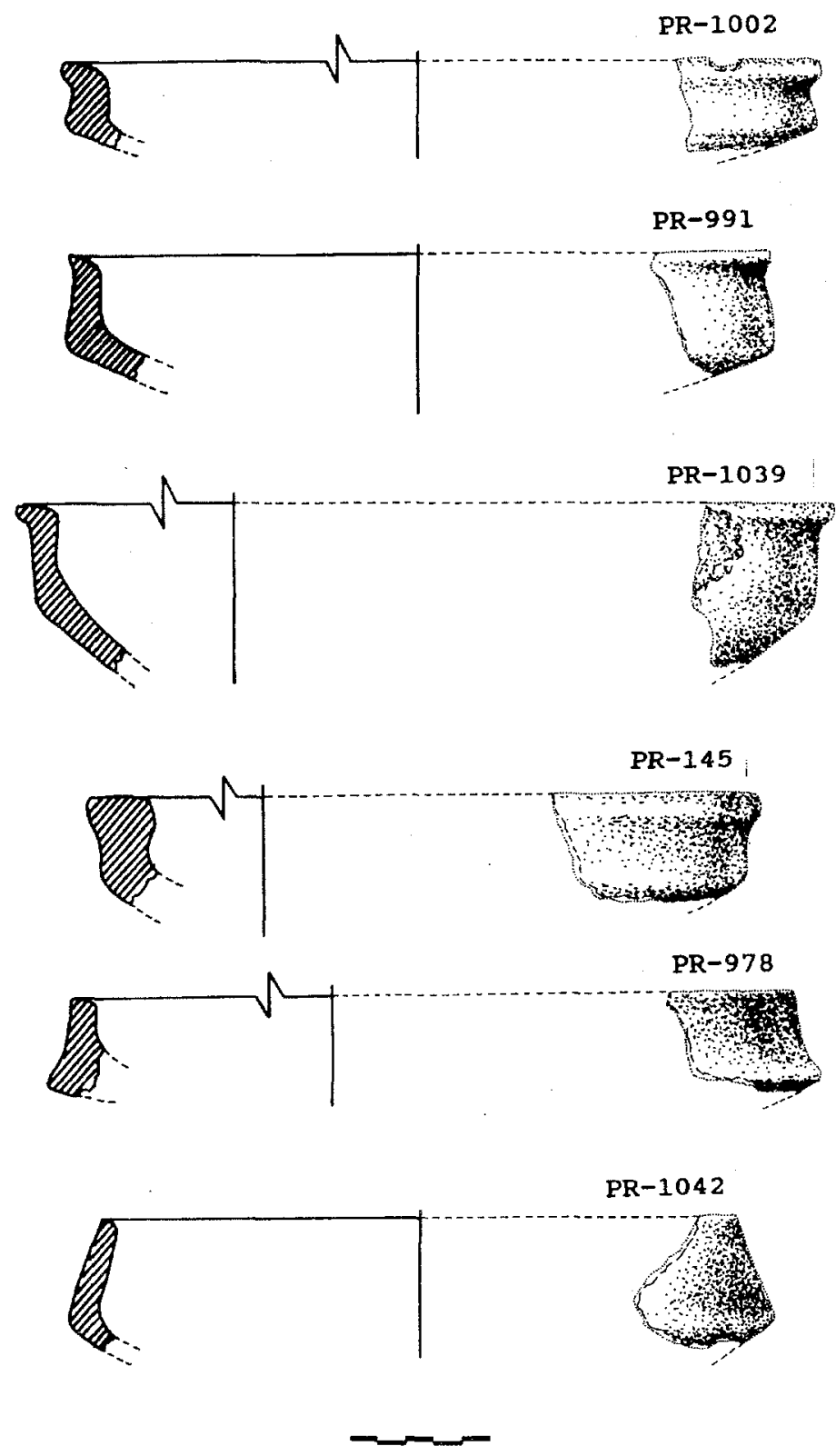

Figura 10. LAMESA. Cazuelas carenadas. 
El tránsito neolítico-calcolítico en el sureste de Córdoba. Su evolución...

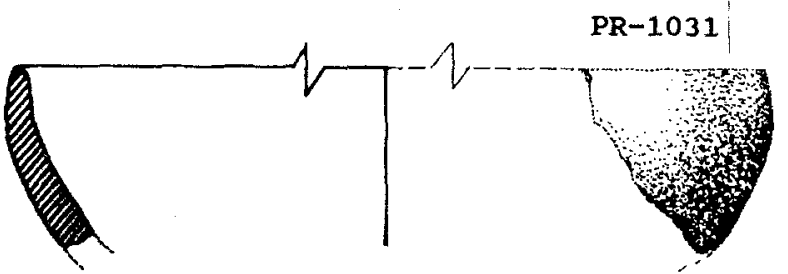

PR-1008;
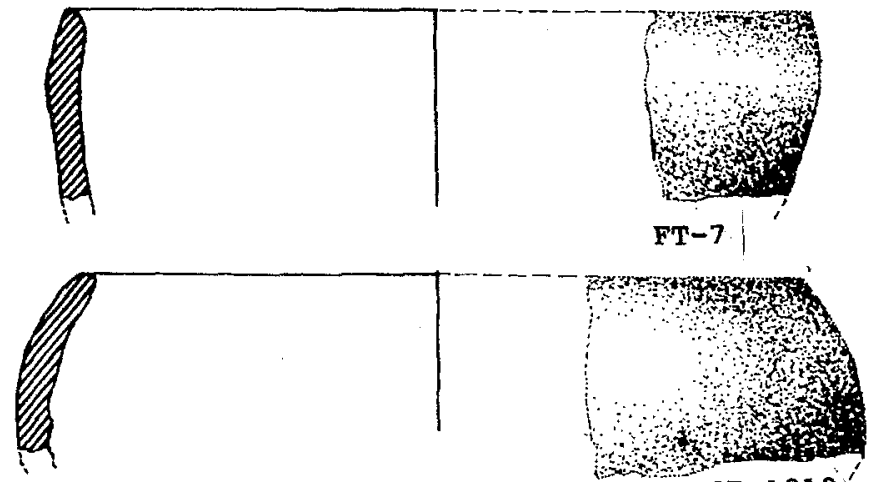

PR-1018!
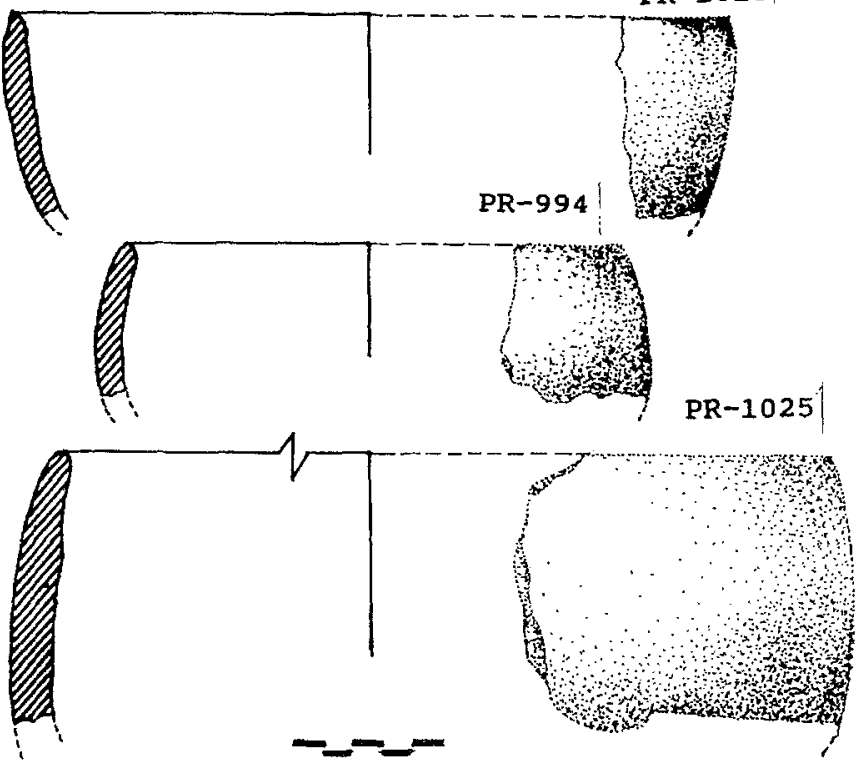

Figura 11. LAMESA. Cuencos. 
PR-944

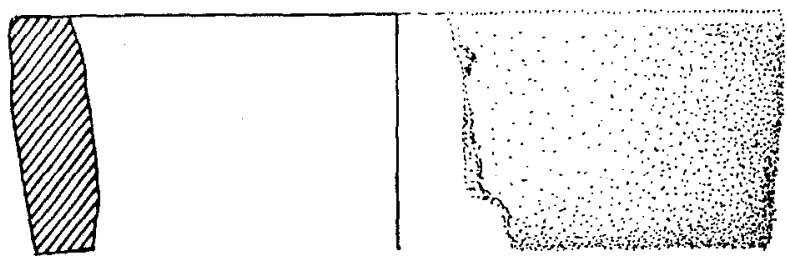

\section{PR-945}
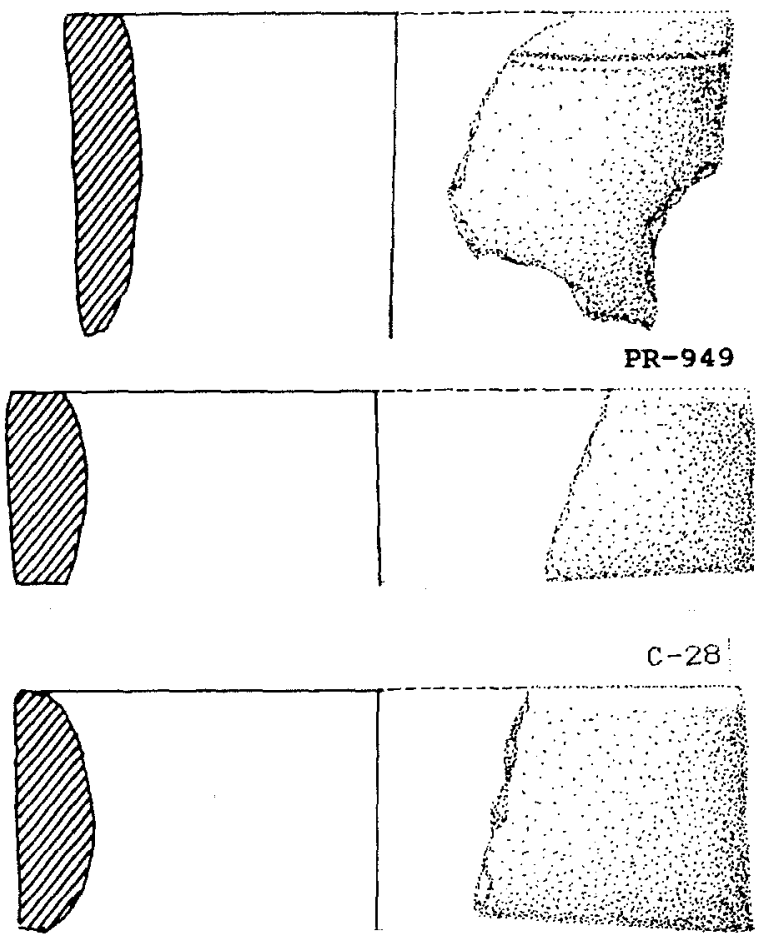

Figura 12. LAMESA. Brazaletes. 


\section{EL CONTEXTO GENERAL ANDALUZ}

El desarrollo de recientes Proyectos de Investigación así como las excavaciones, tanto sistemáticas como de urgencia, practicadas en numerosos yacimientos van facilitando la obtención de una amplia secuencia desde el Neolítico hasta el Bronce. En ciertas zonas, en especial el Bajo Guadalquivir, se nos presentan mayores dificultades para conformar secuencias continuas debido a la escasez de poblados excavados que abarquen este lapso cronológico, de tal forma que no podemos llegar a conocer con mayor exactitud cómo tiene lugar el tránsito del Neolítico al Calcolítico, en cambio, sí podemos hilvanar la evolución histórica a través de la contrastación con otros yacimientos.

Lo primero que queremos destacar es la contradicción que se da entre los diferentes investigadores a la hora de referirse al Neolítico Final. Algunos caracterizan con este término a unos conjuntos industriales definidos por una continuidad manifiesta con la ergología propia del Neolítico Medio andaluz, estribando la mayor diferencia en el detrimento de las cerámicas decoradas frente a las no decoradas, empobrecimiento general de las industrias líticas talladas, ornamental y ósea, junto a un «aumento» de la piedra pulimentada. Económicamente, se definiría por la continuidad de los modos que se desarrollan en el Neolítico Medio de forma generalizada $\mathrm{y}$, con respecto al hábitat, parece documentarse un mayor desarrollo de los poblados al aire libre. Este es el modelo que nosotros consideramos como definitorio del Neolítico Final andaluz y representado en las estratigrafías clásicas como Nerja (Málaga) (Pellicer, 1987a, 1987b, 1990), cueva Chica de Santiago (Sevilla) (Acosta, 1986), cueva del Canjorro (Jaén) (Carrasco y Medina, 1983), la Dehesilla (Cádiz) (Acosta y Pellicer, 1990), Parralejo (Cádiz) (ACOSTA, 1986), Murciélagos de Zuheros (Córdoba) (Gavilán et al., 1994), Mármoles (Córdoba) (Asquerino, 1990), Papa Uvas (Huelva) (Martín de la Cruz, 1986), etc.

Las estratigrafías típicas del Neolítico andaluz nos muestran una perduración del Neolítico Final hasta un momento avanzado del Calcolítico, durante el cual empezamos a detectar muestras más evidentes de transformación.

Por el contrario, para otros investigadores, el Neolítico Final está representado por el denominado "Horizonte de las Cazuelas Carenadas", el hábitat al aire libre mayoritariamente y una economía agrícola, de corte cerealista, mucho más desarrollada que argumentan mediante la existencia de numerosas estructuras siliformes y en forma de zanjas. Este segundo modelo sólo se ha constatado en yacimientos al aire libre, siendo 
paradigmáticos La Marismilla (Sevilla) (Escacena, 1994), Los Castillejos de Montefrío (Granada) (Arribas y Molina, 1979), etc.

Por tanto, tras esta contradictoria definición del Neolítico Final, resulta difícil de valorar la documentación relativa a los momentos transicionales. Se ha diferenciado un horizonte, indistintamente adjudicado, según los investigadores, al Neolítico Final o al Calcolítico Inicial, con hábitats en poblados y sin sistemas de defensa artificiales, estructuras siliformes, etc. En la cultura material destaca la continuidad de ciertas formas cerámicas y esquemas decorativos de raíz neolítica, siendo de especial relevancia la perduración de la almagra a pesar de su evidente pérdida de calidad, y la aparición de un complejo material nuevo, como las cazuelas carenadas, cuencos, largas hojas de sílex, puntas de flecha, «elementos de hoz», placas de arcilla perforadas, una mayor proliferación de elementos pulimentados y piezas activas y pasivas de molturación...

Un segundo horizonte, considerado cultural y cronológicamente como Calcolítico Inicial o Pleno, según los diferentes investigadores, representa una fase de esplendor y se caracteriza por la localización de poblados en zonas de altura y fácil defensa, que a su vez, son reforzados por sistemas artificiales, controlando vías naturales de comunicación y una amplia variedad de recursos. La cultura material viene representada por platos de borde engrosado, cuencos, dientes de hoz, crecientes, puntas de flecha de base cóncava, elementos cultuales y algunos elementos metálicos.

\section{EL TRÁNSITO EN LA SUBBÉTICA CORDOBESA}

Como es lógico pensar, un sólo yacimiento no nos puede arrojar mucha luz para determinar cómo se produjo el tránsito entre el Neolítico y el Calcolítico en este sector, por tanto, es necesario interrelacionarlo con otros situados en el mismo ámbito. En este sentido, hemos de decir que estas etapas de tránsito son difíciles de cuantificar dada la dificultad en atisbar las transformaciones paulatinas que albergan rasgos innovadores y otros continuadores.

Para el Neolítico Final contamos con los enclaves de la cueva de los Murciélagos de Zuheros, Mármoles, Murcielaguina, Cholones o Huerta Anguita, en Priego de Córdoba, que cuentan con materiales adjudicables al Neolítico Final y al Cobre (Gavilán, 1989), tratándose, en estos momentos neolíticos, de cuevas de habitación, aunque parece que posteriormente algunas de ellas cumplieron una función funeraria o se relacionan con la explotación de recursos estacionales muy concretos. En Murciélagos de 
Zuheros, tras unos niveles caracterizados por el aumento de la cerámica no decorada en detrimento de la decorada, el enrarecimiento del adorno y la industria ósea, se superponen otros con una ergología propia de la fase plena del Cobre, representada por platos de borde engrosado, dientes de hoz, cuencos, cerámicas pintadas, largas láminás de sílex, etc (Gavilán et al., 1994).

Los yacimientos calcolíticos más interesantes, sin olvidar que no se ha realizado ninguna excavación arqueológica en ellos y, excepto La Mesa, parece que no presentan una ocupación anterior a este momento, se localizan en cerros amesetados situados en los rebordes montañosos de estos conjuntos serranos, como es el caso de la Fuente del Río (Cabra), El Laderón (Doña Mencía), La Mesa (Fuente-Tójar) y, finalmente, El Castillarejo (Almedinilla). Estos cuatro yacimientos controlan, no sólo buenas tierras de labor y un amplio territorio, sino también el acceso hacia los pastos de las sierras y las vías de comunicación que marcan los cursos fluviales.

Otros yacimientos se localizan en zonas más interiores de la Subbética, como El Torreón del Esparragal (Priego) - de posible raigambre neolítica--, El Castellar (Almedinilla) o el Castillejo (Carcabuey), los cuales controlan pasos naturales, bien mediante cursos fluviales de menor entidad, bien mediante pasillos serranos naturales.

Consideramos que esta disposición de los asentamientos evidencia un control económico intencionado del territorio en el que coexisten unos asentamientos con preocupaciones no sólo claramente defensivas sino de dominio del territorio, tanto de campiña como de sierra, y de explotación de las buenas tierras de labor que los rodean, y otros que ejercen control sobre las zona internas de estos conjuntos serranos.

A tenor de los restos aportados por todos los yacimientos analizados $y$, sobre todo teniendo en cuenta la estratigrafía de Murciélagos de Zuheros, única secuencia amplia con la que se cuenta en la zona, consideramos dos situaciones hipotéticas durante el tránsito al Calcolítico Inicial de la Subbética Cordobesa:

La primera posibilidad sería el abandono de esta zona como lugar de hábitat al finalizar el Neolítico, la cual consideramos difícil de aceptar teniendo en cuenta el desarrollo más que considerable del Neolítico en este sector y sus posibilidades económicas potenciales.

Como segunda posibilidad, se podría plantear el enquistamiento de los grupos pertenecientes al Neolítico Final que quedan ajenos al relativo cambio que supone el inicio de un nuevo período hasta los momentos finales del Cobre Inicial o los comienzos del Pleno. 
Con respecto al tránsito Neolítico-Calcolítico e independientemente de las dos hipótesis apuntadas, lo que sí parece palpable es que determinadas cuevas que habían venido ocupándose desde el Neolítico continúan frecuentándose, aunque no de una forma tan intensa y seguramente destinadas a lugares de enterramiento o a ocupaciones relacionadas con la explotación de unos recursos estacionales muy concretos. Por su parte, se afianza el asentamiento al aire libre, especialmente en aquellos núcleos amesetados, próximos a cursos de agua y ejerciendo un buen control visual sobre el territorio.

En resumen, y para terminar, pensamos que este sector, de gran vigor durante el Neolítico, continuó con una importante ocupación durante el Cobre siguiendo un desarrollo evolutivo marcado por la tradición anterior aunque abierto a novedades procedentes de centros más dinámicos. Esperamos tener la oportunidad de continuar nuestros trabajos en la Subbética y que futuras excavaciones ayuden a resolver algunos de los interrogantes aquí planteados ${ }^{3}$.

\section{BIBLIOGRAFIA ${ }^{4}$}

Acosta Martinez, P. (1986): «El Neolítico en Andalucía Occidental: Estado actual». Homenaje a Luis Siret (Cuevas de Almanzora, 1984): 136-151. Sevilla.

Acosta, P.; Pellicer, M. (1990): La cueva de la Dehesilla (Jerez de la Fra.). Las primeras civilizaciones productoras en Andalucia Occidental. Jerez de la Frontera (Cádiz).

Arribas, A.; Molina, F. (1979): «El poblado de los Castillejos en las Peñas de los Gitanos (Montefrío, Granada). Campaña de Excavaciones de 1971. El Corte 1». C.P.U.G. Serie Monográfica 3. Granada.

AsQUERINO FERNÁNDEZ, M.D. (1978): “Análisis estadístico y tipológico de materiales sin estratigrafía (1971-1974)". Saguntum-Plav 13: 99-225. Valencia.

Asouerino, M.D. (1990): «Excavaciones en la cueva de los Mármoles de Priego de Córdoba. Resultados preliminares". Antiquitas 1: 8-11. Priego de Córdoba.

Bernier, J.; SánChez, C.; JIMÉNEZ, A.; SÁnChEZ, A. (1981): Nuevos yacimientos arqueológicos en Córdoba y Jaén. Córdoba.

CarRasco, J.; Meoina, J. (1983): «Excavaciones en el complejo cavernícola de El Canjorro (Jaén). Cueva 3». XVI C.A.N. (Cartagena, 1982): 371-381. Zaragoza.

C.E.B.A.C. (1971): Estudio agrobiológico de la provincia de Córdoba. Córdoba.

DELGADO FERNÁNDEZ, M.R. (1995): El tránsito entre las Primeras Sociedades Productoras y las Culturas de la Metalurgia en el sureste de Córdoba. Evolución y desarrollo: La Mesa. Servicio de Publicaciones de la Universidad de Córdoba.

Díaz del Olmo, F.; Alvarez, G. (1989): «Formaciones kársticas, Espeleogénesis y Morfoclimas fríos (Béticas Occidentales). Episodios Cuaternarios". El Cuaternario en Andalucía Occidental. AEQUA Monografías 1: 67-86. Sevilla.

3 Este trabajo se inscribe dentro del "Proyecto Prehistoria y Protohistoria de Córdoba", Grupo de Investigación del P.A.l. 505100, concedido y subvencionado por la Consejería de Cultura de la Junta de Andalucía.

4 Para una bibliografía más especifica nos remitimos a DELGADO, M. (1995). 
Escacena Carrasco, J.L. (1994): «Acerca de la producción de sal en el Neolítico Andaluz». Arqueología en el Entorno del Bajo Guadiana: 91-118. Hueiva.

Gavilán Ceballos, B. (1989): El Neolítico en el Sur de Córdoba. Anexos de Estudios de Prehistoria Cordobesa. Córdoba.

Gavilán, B.; Vera, J.C.; Peña, L.; Cepillo, J.; Delgado, M.; Marfil, C. (1994): «Preliminares sobre la tercera campaña de Excavación Arqueológica de Urgencia en la Cueva de los Murciélagos de Zuheros (Córdoba)". Antiquitas 5: 5-12. Priego de Córdoba.

Martín dE LA CRUZ, J.C. (1986): «Papa Uvas Il. Campañas 1981-83 (Aljaraque, Huelva)». E.A.E. 149. Madrid.

Martinez Santa-OLALLA, J. (1935): «Cueva neolítica andaluza». S.E.A.E.P. XIV: 259-260.

MuRILlo REDONDO, J.F. (1990): «Estado de la cuestión sobre el poblamiento durante el Calcolitico y la Edad del Bronce en las Subbéticas Cordobesas". A.A.C. 1: 53-80. Córdoba.

Ortega Alba, F. (1974): El sur de Córdoba. Estudio de Geografía Agraria. Córdoba.

Pellicer Catalán, M. (1987a): «Cueva de Nerja (Málaga): Corte NM-85 (Postpaleolítico). A.A.A. (1985) II: 227-232. Sevilla.

Pellicer, M. (1987b): «Informe sobre las excavaciones arqueológicas en la Cueva de Nerja (Málaga)». A.A.A. (1986) II: 325-329. Sevilla.

PElloicer, M. (1990): «Informe sobre las excavaciones arqueológicas en la Cueva de Nerja (Málaga), Cámara de la Torca (1987)». A.A.A. (1987) 11: 271-275. Sevilla. 